\title{
Grafting Cellulose Nanocrystals With Phosphazene-containing Compound for Simultaneously Enhancing the Flame Retardancy and Mechanical Properties of Polylactic Acid
}

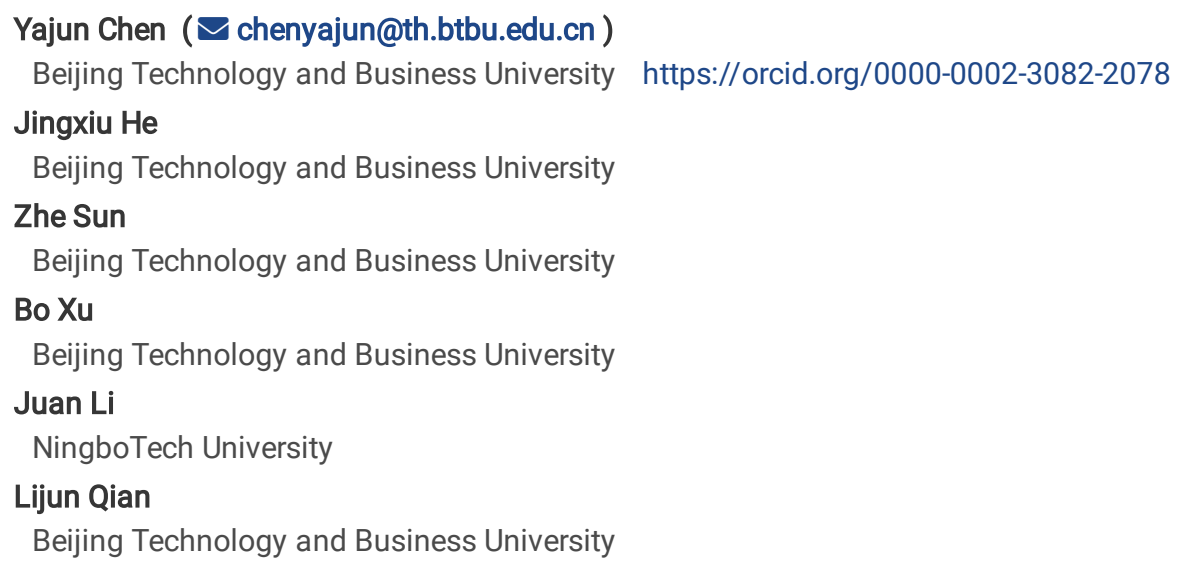




\section{Abstract}

Cellulose nanocrystals (CNCs) have been used as bio-based carbon source in intumescent system. However, CNCs have the disadvantages of low onset decomposition temperature and decompose and carbonize during processing. We, herein, demonstrated the design of phosphazenecontaining CNCs (P/N-CNCs) with great thermal stability and outstanding charring ability. The TGA results showed that the initial decomposition temperature of P/N-CNCs was increased from $202.4{ }^{\circ} \mathrm{C}$ to $272.2^{\circ} \mathrm{C}$ (increased by $34.5 \%$ ), and the residual char at $700{ }^{\circ} \mathrm{C}$ was increased from 24.9 wt\% to 55.8 wt\% compared with CNCs. Then, flame retardant PLA composites were prepared by blending PLA, P/N-CNCs with ammonium polyphosphate (APP), melamine (MPP), aluminum hypophosphite (AHP) and piperazine pyrophosphate (PPAP), respectively. The thermal stability, flame retardant properties and mechanical properties of PLA composites were investigated. The results showed that the flame retardant system constructed by 7 wt\% APP and 3 wt\% P/N-CNCs had the best effect in PLA. PLA/7APP/3P/N-CNCs had the highest limit oxygen index value (28.1\%), the lowest peak heat release rate $\left(266 \mathrm{~kW} / \mathrm{m}^{2}\right)$ and reached UL $94 \mathrm{~V}-0$ rating. Moreover, the tensile strength, impact strength and elongation at break of PLA/7APP/3P/N-CNCs were increased by $7.3 \%, 18.6 \%$ and $29.4 \%$, respectively, compared with these properties of PLA/7APP/ 3CNCs. This work provides a new idea for the design of CNCs with great thermal stability and outstanding charring ability, and offers a new method for the preparation of high-performance flame-retardant PLA composites.

\section{Introduction}

With the aggravation of environmental pollution and the shortage of petroleum-based raw materials, renewable resources have gained increasing attention (Sombatsompop et al. 2021; Hubbe et al. 2021; Lyas et al.2021). Polylactic acid (PLA), as one of the degradable thermoplastic polymers, obtains from renewable resources such as corn starch (Xu et al. 2019). It has the advantages of low toxicity, environmental friendliness and good mechanical properties (Xiong et al. 2019; Sharma et al. 2021; Liu et al.2021). It has been widely used in medical, textile and food packaging fields and is expected to replace traditional non-degradable petroleum-based raw materials (Benito et al. 2020; Jing et al. 2018; Zhang et al. 2021). However, PLA is flammable and drops seriously in the combustion process (Chen et al. 2016), which limits its application in electronics, electric appliances, automobiles and other fields that demand high flame retardant performance (Zhang et al. 2021). Therefore, it is necessary to develop flame retardant PLA composites.

Researchers have found that halogen flame retardants could effectively improve the flame retardant properties of polymers (Liu et al. 2020). However, with the increase of awareness of environmental protection and the requirements of environment-related regulations, halogen-free flame retardants have become an emerging research hotspot in the field of flame retardant (Liu et al. 2021; Chen et al. 2020; Sai et al. 2021; Chen et al. 2018). Among them, intumescent flame retardant (IFR) plays an important role in improving the thermal stability and flame retardant performance of PLA (He et al. 2020). It is well known that carbon source is a very important component of IFR. Conventional carbon sources were not degradable and non-renewable. In order to maintain the biodegradability of PLA, it is necessary to develop biodegradable carbon sources.

Some biodegradable materials, such as lignin, chitosan and cyclodextrin, which contain a large amount of hydroxyl groups, were natural carbon sources (Li et al. 2018; Costes et al. 2017; Chen et al. 2020; Song et al. 2018; Zhang et al. 2018; Luda et al. 2019; Zhang et al. 2020; Yang et al. 2020). The researchers found that they improved the flame retardant performance of PLA while maintaining its environmental friendliness. Wang et al. (Wang et al. 2013) blended polypseudorotaxane (PPR), an inclusion compound with cyclodextrin $\beta$-CD as the main body, APP/melamine (MA) system and PLA to prepare flame retardant PLA composites. Compared with PLA1(containing 10\% APP/5\% MA/5\% $\beta$-CD), the peak heat release rate (pk-HRR) and total heat release (THR) of PLA2 (containing 10\% APP/5\% MA/5\% PPR) were reduced by $20 \%$ and $13 \%$, respectively. Maqsood et al. (Maqsood et al. 2019) mixed APP with lignin KL and then melted and blended with PLA. It was found that compared with pure PLA (LOI=20.1\%), the LOI value of PLA/ 20\% APP/5\% KL composite increased to $37.8 \%$, the pk-HRR and THR decreased by $50 \%$ and $20 \%$, respectively. After combustion, the carbon layer with certain thickness and uniform distribution was produced. Chen et al. (Chen et al. 2017) prepared PLA-C2A5 by adding CS and APP into PLA through melt-blending with the mass fraction of 2:5. Compared with pure PLA (LOI=20.0\%), PLA composite containing 7\% C2A5 has a LOI value of 33\%, and the pk-HRR decreases by $17 \%$. Maqsood et al. ( Maqsood et al. 30) used starch (ST) as a carbon source and combined with acid source APP to form IFR system for flame retardant PLA. It was found that compared with PLA/20\% APP (LOI=31.9\%), the LOI value of PLA/20\% APP/7\% ST increased to 37.3\%, the pk-HRR and THR decreased by $43 \%$ and $37 \%$, respectively, and the residual char increased from 23 wt $\%$ to 43 wt $\%$.

Nanocelluloses were rich in source and high in carbon content, including cellulose nanofiber (CNF), cellulose nanocrystals (CNCs) and so on (Thomas et al. 2018; De France et al. 2017; Abraham et al. 2016). Cellulose nanocrystals have excellent mechanical strength, stiffness and big length-diameter ratio compared with ordinary size cellulose (Thomas et al. 2018). It is easy to form uniform microstructure when added into PLA, which is beneficial to improve the mechanical properties of composites (Mohammadi et al. 2021). However, natural cellulose and its derivatives are easy to decompose, easy to burn and difficult to carbonize in combustion (Feng et al. 2017). Chemical modification of cellulose nanocrystals can solve the above problems. The reported modification methods mainly include silanization, amidation, esterification, 
etherification, polymerization and other surface modification technologies (Ruiz-Palomero et al. 2015; Mekonnen et al. 2021; Szefer et al. 2021; Tajmoradi et al. 2021; Che et al. 2020).

In order to improve the thermal stability and char-forming ability of CNCs, flame retardant cellulose nanocrystals (P/N-CNCs) containing phosphazene group were obtained by chemically grafting the modification agent with phosphazene group on the surface of CNCs in this study. Then, P/N-CNCs were combined with APP or other phosphorus-containing flame retardants to construct an intumescent flame retardant system for PLA. This paper mainly studies the influence of P/N-CNCs and APP on the thermal stability, the flame retardant properties and the mechanical properties of PLA composites, as well as their synergistic flame retardant action mechanism in PLA.

\section{Experimental}

\subsection{Materials}

The modification agent containing phosphazene groups was prepared in our laboratory by the reaction of $\mathrm{Y}$-aminopropyl triethoxysilane (KH550) and hexachlorocyclotriphosphazene (HCCP). Its structure is shown in Fig. 1 and the results of FTIR and NMR of the modification agent are shown in the supplementary materials. CNCs were purchased from Chongqing Nayan New Material Technology Co., Ltd (China). Ethanol was provided by Sinopharm Chemical Reagent Co., Ltd. (China) and was analytical rating. APP (degree of polymerization $>1000$ ) was provided by Hangzhou JLS Flame Retardants Chemical Co., Ltd (China). Aluminum hypophosphite (AHP) was provided by Qingdao Fusilin Chemical Co., Ltd (China). Melamine polyphosphate (MPP) was provided by Qingdao Haida Chemical Co., Ltd (China). Piperazine pyrophosphate (PPAP) was synthesized by our laboratory. PLA resin (2003D) was obtained from Nature Works (U.S.A.).

\subsection{Synthesized of the $P / N-C N C S$}

The schematic representation for the synthetic route to P/N-CNCs is shown in Fig. 2(French AD. 2017). First, $8.2 \mathrm{~g}$ CNCs and $60 \mathrm{ml}$ deionized water were pre-mixed and ultrasonized for $30 \mathrm{~min}$. Then, the mixture was placed in a $500 \mathrm{ml}$ three-point flask containing the thermometer reflux condenser and a mechanical stirrer, and gradually heated to $80^{\circ} \mathrm{C}$ in $\mathrm{N}_{2}$ atmosphere. Subsequently, a mixture containing modification agent $(20.7 \mathrm{~g})$ and ethanol $(100 \mathrm{ml})$ was dropped to the flask through a constant pressure drop funnel at a rate of 2 drops/s, which was allowed to react at $80{ }^{\circ} \mathrm{C}$ for $12 \mathrm{~h}$. The precipitate was collected by centrifugation, and then washed with deionized water at least three times. After drying, the flame retardant cellulose nanocrystals containing phosphazene group (P/N-CNCs) were obtained. The product was yellow solid powder.

\subsection{Preparation of PLA composites}

As shown in Table 1, the addition amount of IFR flame retardant in PLA matrix is 10 wt\%. PLA, P/N-CNCs, APP, MPP, AHP and PPAP were dried in a vacuum drying oven at $100{ }^{\circ} \mathrm{C}$ for $8 \mathrm{~h}$ in advance. Pure PLA and flame retardants were added into a torque rheometer, and the PLA composite was prepared by melting and blending for $7 \mathrm{~min}$ at a roll speed of $50 \mathrm{rpm}$. Then the mixtures were transferred to customized molds. The working process of the tablet press was as follows: preheated for 6 min, venting for 5 times, pressed holding for 5 min at 10 MPa, and then cooled to room temperature. Finally, standard test samples were obtained.

Table 1. The formulations of PLA composites.

\begin{tabular}{|llllllll|}
\hline Samples & PLA & CNCs & P/N-CNCs & APP & MPP & AHP & PPAP \\
& $(w t \%)$ & $(w t \%)$ & $(w t \%)$ & $(w t \%)$ & $(w t \%)$ & $(w t \%)$ & $(w t \%)$ \\
\hline Pure PLA & 100 & 0 & 0 & 0 & 0 & 0 & 0 \\
\hline PLA/10APP & 90 & 0 & 0 & 10 & 0 & 0 & 0 \\
\hline PLA/7APP/3CNCs & 90 & 3 & 0 & 7 & 0 & 0 & 0 \\
\hline PLA/7APP/3P/N-CNCs & 90 & 0 & 3 & 7 & 0 & 0 & 0 \\
\hline PLA/7MPP/3P/N-CNCs & 90 & 0 & 3 & 0 & 7 & 0 & 0 \\
\hline PLA/7AHP/3P/N-CNCs & 90 & 0 & 3 & 0 & 0 & 7 & 0 \\
\hline PLA/7PPAP/3P/N-CNCs & 90 & 0 & 3 & 0 & 0 & 0 & 7 \\
\hline
\end{tabular}

\subsection{Characterizations}

Fourier transform infrared spectrum (FTIR) were recorded on a Nicolet iN10MX-type spectrometer (USA) The samples were mixed with KBr particles and then tested in a wavelength range of 4000 to $500 \mathrm{~cm}^{-1}$. 
The morphologies of CNCs and P/N-CNCs were observed using a JEM-1200EX transmission electron microscopy (TEM, Japan). The test voltage was $200 \mathrm{kV}$.

X-ray photoelectron spectroscopy (XPS) spectra were obtained on EscaLab Xi+ equipment (Thermo Scientific, America). The vacuum degree of the analysis chamber was $8 \times 10^{-10} \mathrm{~Pa}$ and the working voltage was $14.4 \mathrm{kV}$.

X-ray diffraction (XRD) was carried out using a Rigaku X-ray generator (Bruker, Germany) at room temperature. The test angle ranges from $5^{\circ}$ to $90^{\circ}$ and the operating voltage was $40 \mathrm{kV}$.

The thermal stability was carried out on the simultaneous Thermogravimetric analyzer (TGA) STA 8000 (PerkinElmer, USA). The sample weight should be in the range of $5 \sim 10 \mathrm{mg}$. An alumina crucible was chosen to load the sample. The heated rate was $20^{\circ} \mathrm{C} / \mathrm{min}$ and the temperature range was $50{ }^{\circ} \mathrm{C}$ to $700{ }^{\circ} \mathrm{C}$.

The limited oxygen index (LOI) values were determined by Dynwasco LOI instrument (Fire Testing Technology, UK). ASTM D2863-97 was used in the test. The dimension of the sample was $130.0 \times 6.5 \times 3.2 \mathrm{~mm}^{3}$. The test was repeated three times for each specimen, and the average value was calculated as the final result.

The UL94 vertical burning test was carried out on a FTT0082 combustion chamber. The used standard was ASTM D 3801, and the required sample size was $125.0 \times 12.7 \times 3.2 \mathrm{~mm}^{3}$. Five same samples were used for each test. The burning time and the burning rating were recorded and listed in the table.

According to ISO 5660 standard, FTT cone calorimeter (CCT, Fire Testing Technology, UK) was applied to measure the fire behavior of each sample. The heat flux was $50 \mathrm{Kw} / \mathrm{m}^{2}$. The sample dimension was $100 \times 100 \times 3 \mathrm{~mm}^{3}$.

The char layer morphologies after CCT were observed by PhenomTM Pro scanning electron microscope (SEM, Phenom World, Netherlands). The test was carried out under high vacuum conditions, and the accelerating voltage was $10 \mathrm{kV}$.

The mechanical properties were tested in accordance with ISO 527-1. The tensile strength tests were carried out on CMT6104 universal testing machine (MTS systems Co. Ltd., China). The test speed was $5 \mathrm{~mm} / \mathrm{min}$. The unnotched impact strength was measured on an XJZ-50 digital impact test machine (Cheng De testing machine Co. Ltd., China) with a $2 \mathrm{~J}$ pendulum. The dimensions of the samples were $80 \times 10 \times 4 \mathrm{~mm}{ }^{3}$. Five specimen were tested for each of the sample with the average value used as the final data.

\section{Results And Discussion}

\subsection{Structural characterization and performance testing of $P / N-C N C s$}

The structure and the thermal stability of P/N-CNCs were further characterized by FTIR, XPS, XRD and TGA. Fig. 3a is the infrared spectrum of $\mathrm{P} / \mathrm{N}-\mathrm{CNCs}$. By comparing with CNC curves, it was found that the peak strength ratio of O-H bond to $\mathrm{C}-\mathrm{H}$ bond in $\mathrm{P} / \mathrm{N}-\mathrm{CNC}$ curve decreased (Ling et al. 2019). On the one hand, some hydroxyl groups in CNCs dehydrated with the hydrolyzed modification agent, resulting in the reduction of the number of hydroxyl groups. On the other hand, the modification agent with phosphazene group contains $\mathrm{C}-\mathrm{H}$ bond, which made the increase of $\mathrm{C}-\mathrm{H}$ bond in the system. As a result, the peak strength ratio of $\mathrm{O}-\mathrm{H}$ bond to $\mathrm{C}-\mathrm{H}$ bond decreased. It was also observed that the $\mathrm{P} / \mathrm{N}-\mathrm{CNC}$ curve showed a dentate peak in the wave number range of $1100 \mathrm{~cm}^{-1}$, which was due to the typical absorption peak of Si-O bond contained in the modification agent (Chen et al. 2018). Based on the above analysis, it suggests that the modification agent has been successfully grafted onto CNCs.

The chemical compositions of CNCs and P/N-CNCs were analyzed by X-ray photoelectron spectroscopy. Fig. 3b shows the XPS curves of CNCs and P/N-CNCs, and the corresponding data are listed in Table 2. As shown in Fig. 3b, the peaks at $101 \mathrm{eV}$ represented Si2p, 153 eV represented P2p, 285 eV represented C1s, $398 \mathrm{eV}$ represented N1s and $532 \mathrm{eV}$ represented 01s respectively. In addition, it can be seen from Table 2 that the contents of $\mathrm{C}$ element and $\mathrm{O}$ element in CNCs were $46.8 \mathrm{wt} \%$ and $53.2 \mathrm{wt} \%$ respectively, while in P/N-CNCs, there were 3.1 wt $\%$ N, 2.5 wt $\%$ P and $5.4 \mathrm{wt} \% \mathrm{Si}$ in addition to $41.2 \mathrm{wt} \% \mathrm{C}$ and $47.8 \mathrm{wt} \% \mathrm{O}$. It indicates that the modified CNCs contain nitrogen, phosphorus and silicon elements.

The crystal structures of CNCs after chemical grafting were studied by X-ray diffraction (Fig. 3c). There were three typical diffraction peaks at $2 \theta=14.6^{\circ}, 16.5^{\circ}$ and $22.6^{\circ}$ in CNC, corresponding to the (100), (010) and (110) crystal faces of type I cellulose, respectively (French AD. 2014). It could be seen clearly from the XRD curves of P/N-CNCs that its peaks at $2 \theta=14.6^{\circ}, 16.5^{\circ}$ and $22.6^{\circ}$ were almost the same as the typical diffraction peaks of CNC, and the relative intensity does not change significantly. In addition, a new diffraction peak appears at $2 \theta=11.5^{\circ}$, which was caused by the crystal structure of the modification agent with phosphazene group (Feng et al. 2017), indicating that the modification agent was successfully grafted onto the surface of CNCs and had no effect on the crystal structures of CNCs. 
Thermal stability of CNCs before and after modification was evaluated by TGA. The initial decomposition temperature (the temperature at $5 \%$ mass loss, $\left.T_{5 \%}\right)$, the maximum decomposition temperature $\left(T_{\max 1}\right.$ and $\left.T_{\max 2}\right)$ and the residual char at $700{ }^{\circ} \mathrm{C}$ are shown in Table 3 . Both CNCs and P/N-CNCs had two stages of decomposition in $\mathrm{N}_{2}$ atmosphere. As shown in Fig. $3 \mathrm{~d}$ and Table 3 , the $T_{5 \%}\left(272.1^{\circ} \mathrm{C}\right)$ and $T_{\text {max } 1}$ and $T_{\max 2}\left(340.9^{\circ} \mathrm{C}\right.$ and $\left.413.2^{\circ} \mathrm{C}\right)$ of $\mathrm{P} / \mathrm{N}$-CNCs were all much higher than those of $\mathrm{CNCs}\left(202.4^{\circ} \mathrm{C}, 272.2^{\circ} \mathrm{C}\right.$ and $\left.373.5^{\circ} \mathrm{C}\right)$, indicating that the thermal stability of CNCs could be greatly improved by grafting the modification agent onto the surface of CNCs. This is because the modification agents grafted on the surface of CNCs are polycondensation structures, rather than small molecules. This polycondensation structures have better thermal stability, which is conducive to the improvement of the thermal stability of CNCs. In addition, it can be seen from Table 3 that the residual char of P/N-CNCs at $700{ }^{\circ} \mathrm{C}$ was $55.8 \mathrm{wt} \%$, which was more than double of CNCs (24.9 wt\%), indicating that the modified CNCs (P/N-CNCs) had better char-forming ability.

Table 2. Surface elemental analysis of CNCs and P/N-CNCs obtained from XPS

\begin{tabular}{|llllll|}
\hline Samples & $\mathrm{C}$ & $\mathrm{O}$ & $\mathrm{N}$ & $\mathrm{P}$ & $\mathrm{Si}$ \\
& $(\mathrm{wt} \%)$ & $(\mathrm{wt} \%)$ & $(\mathrm{wt} \%)$ & (wt\%) & (wt\%) \\
\hline modification agent & 36.3 & 25.4 & 9.0 & 7.8 & 21.5 \\
\hline CNCs & 46.8 & 53.2 & - & - & - \\
\hline P/N-CNCs & 41.2 & 47.8 & 3.1 & 2.5 & 5.4 \\
\hline
\end{tabular}

Table 3. Thermal behavior and charring parameters of CNCs and P/N-CNCs under $\mathrm{N}_{2}$ atmosphere

\begin{tabular}{|c|c|c|c|c|}
\hline \multirow[t]{2}{*}{ Samples } & \multirow{2}{*}{$\begin{array}{l}T_{\mathrm{d}, 5 \%} \\
\left({ }^{\circ} \mathrm{C}\right)\end{array}$} & \multicolumn{2}{|l|}{$T_{\max }\left({ }^{\circ} \mathrm{C}\right)$} & \multirow{2}{*}{$\begin{array}{l}\text { Residuals at } 700{ }^{\circ} \mathrm{C} \\
\text { (wt\%) }\end{array}$} \\
\hline & & $T_{\max 1}\left({ }^{\circ} \mathrm{C}\right)$ & $T_{\max 2}\left({ }^{\circ} \mathrm{C}\right)$ & \\
\hline CNCs & 202.4 & 272.2 & 373.5 & 24.9 \\
\hline $\mathrm{P} / \mathrm{N}-\mathrm{CNCs}$ & 272.1 & 340.9 & 413.2 & 55.8 \\
\hline
\end{tabular}

The micro morphologies of CNCs were studied by transmission electron microscope to reveal the change caused by modification, and the images are shown in Fig. 4. Fig. $\mathbf{4} \mathbf{a}_{\mathbf{1}}$ and $\mathbf{4} \mathbf{a}_{\mathbf{2}}$ show that the CNCs present rod-like whiskers. After the modification, the sizes and the morphologies of CNCs were both changed. As shown in Fig. $\mathbf{4 a _ { 2 }}$, the diameters of the CNCs before coating are between $10-40$ nm, and as shown in Fig. $\mathbf{4 b}_{1}$, the diameters of the CNCs after modification are about $500 \mathrm{~nm}$. In TEM images, the elements with high relative atomic mass show dark color, while the elements with low relative atomic mass show light color. Thus, the dark spherical aggregates in Fig. $\mathbf{4 b}_{1}$ and $\mathbf{4 b}_{\mathbf{1}}$ are modification agents because the $\mathrm{P}$ and Si elements had high relative atomic mass. The light whiskers are CNCs. The TEM images of P/N-CNCs also indicate that the modification agents with phosphazene group have been grafted to the CNC whiskers.

\subsection{Flame retardancy of PLA composites}

The flame retardant properties of PLA composites were evaluated by limiting oxygen index and vertical combustion tests (Chen et al. 2018; Ma et al. 2021; Zhou et al. 2021; Gao et al. 2020). The test results are shown in Table 4. In Table 4, the LOI value of pure PLA was only 20.1\%, while the LOI values of PLA composites containing flame retardants were significantly increased. It is worth noting that the LOI value of PLA/7APP/3P/N-CNCs was the highest, reaching 28.1\%, which was $11.5 \%$ higher than that of PLA/7APP/3CNCs (25.2\%) and $14.2 \%$ higher than that of PLA/10APP (24.6\%). The vertical burning test results showed that the combustion time of PLA/7APP/3P/N-CNCs was very short, and the total combustion time was only $2.1 \mathrm{~s}$, which was the shortest among all the samples. PLA/7APP/3P/N-CNCs reached UL $94 \mathrm{~V}-0$ rating, while PLA/7APP/3CNCs only reached UL 94 V-2 rating. Although PLA/10APP also reached UL $94 \mathrm{~V}-0$ rating, the combustion time was longer than that of PLA/7APP/3P/N-CNCs. These results implied that after the grafting of modification agent with phosphazene groups, the char-forming performance of $\mathrm{P} / \mathrm{N}-\mathrm{CNCs}$ was improved. Thus, $\mathrm{P} / \mathrm{N}-\mathrm{CNC}$ could play a better synergistic flame retardant effect with APP in the combustion process.

From Table 4, it can also be seen that, the flame retardancy of the composite prepared by adding APP and P/N-CNCs into PLA was obviously better than that of the other three flame retardants (MPP, AHP and PPAP). When MPP or AHP or PPAP were added to PLA/P/N-CNCs system, it was found that the LOI values of these composites were all lower than that of PLA/7APP/3CNCs, and the $t_{1}$ and $t_{2}$ of the material were significantly increased, resulting the UL $94 \mathrm{~V}-2$ rating. in vertical burning test. In addition, it can be clearly seen from Fig. 5 that the drops of PLA/7APP/3P/N-CNCs did not ignite the absorbent cotton (Fig. $5 \mathbf{c}$ ) and passed the UL 94 V-0 rating. However, the droplets of the other three samples in the combustion process could ignite the absorbent cotton (Fig. 5d, $\mathbf{5 e}$ and $\mathbf{5 f}$ ), and all of them were rated as UL94 V-2 rating. Contrast Fig. 5b with Fig. 5c, we found that CNCs were carbonized, indicating that the unmodified CNCs could not meet the processing temperature requirements of PLA. The thermal stability of the modified CNCs were significantly improved, so they were not carbonized during 
the processing of PLA composites. The above results indicated that APP combined with P/N-CNCs were beneficial to improve the LOI value and UL 94 rating of PLA compared with the other three phosphorus-containing flame retardants. Therefore, we only selected APP combined with $\mathrm{P} / \mathrm{N}-\mathrm{CNCs}$ in the later research.

Table 4. The LOI and UL-94 test results of PLA composites

\begin{tabular}{|c|c|c|c|c|c|}
\hline \multirow[t]{3}{*}{ Samples } & \multirow[t]{3}{*}{ LOI (\%) } & \multicolumn{4}{|c|}{ vertical burning test } \\
\hline & & \multicolumn{2}{|c|}{ after-flame time } & \multirow[t]{2}{*}{ UL-94 } & \multirow[t]{2}{*}{ dripping } \\
\hline & & $\mathrm{t}_{1}(\mathrm{~s})$ & $t_{2}(s)$ & & \\
\hline Pure PLA & 20.1 & 48.3 & - & NR & $\mathrm{Y}$ \\
\hline PLA/10APP & 24.6 & 4.8 & 0.9 & V-0 & $\mathrm{Y}$ \\
\hline PLA/7APP/3CNCs & 25.2 & 4.3 & 0.7 & V-2 & $\mathrm{Y}$ \\
\hline PLA/7APP/3P/N-CNCs & 28.1 & 1.8 & 0.3 & V-0 & $\mathrm{Y}$ \\
\hline PLA/7MPP/3P/N-CNCs & 22.4 & 12.4 & 2.2 & V-2 & Y \\
\hline PLA/7AHP/3P/N-CNCs & 22.7 & 14.5 & 3.1 & V-2 & $\mathrm{Y}$ \\
\hline PLA/7PPAP/3P/N-CNCs & 23.7 & 11.7 & 5.8 & V-2 & $\mathrm{Y}$ \\
\hline
\end{tabular}

Cone calorimeter could simulate the real combustion behavior of materials and was widely used to study the combustion behavior of polymer materials (Li et al. 2019). In order to further explore the influence of APP combined with P/N-CNCs on the flame retardancy of PLA, cone calorimeter tests were carried out. In Fig. 6, we could see the heat release rate (HRR) curves and the char yield curves of the samples. The test data are listed in Table 5. As shown in Fig. 6a, pure PLA burned rapidly after ignition and reached the peak within a relatively short time, with a pk-HRR value of $561 \mathrm{~kW} / \mathrm{m}^{2}$ and the total heat release (THR) value of $84.7 \mathrm{MJ} / \mathrm{m}^{2}$. The pk-HRR and THR of PLA were decreased after APP was added to PLA. Compared with pure PLA, the pk-HRR and THR values of PLA/10APP were decreased by $28.9 \%$ and $10.8 \%$, respectively, which indicated that APP could inhibit the combustion of PLA. When $3 \mathrm{wt} \% \mathrm{CNC}$ or P/N-CNCs were added into the PLA/APP system, both of the pkHRR values for PLA/7APP/3CNCs and PLA/7APP/ 3P/N-CNCs were lower than that of PLA/10APP. The pk-HRR value of PLA/7APP/ 3P/NCNCs was $266 \mathrm{~kW} / \mathrm{m}^{2}$, which was the lowest among all the composites.

As shown in Table 5, the total smoke release (TSR) of pure PLA was only $50 \mathrm{~m}^{2} / \mathrm{m}^{2}$. After the addition of $10 \%$ APP, it improved significantly with a value of $280 \mathrm{~m}^{2} / \mathrm{m}^{2}$. Compared to PLA/10APP, the TSR value of the PLA/7APP/3CNCs decreased by $15.0 \%$, while the TSR value of the PLA/7APP/3P/N-CNCs increased by $15.7 \%$. It suggested that the modified CNCs could not inhibit the generation of smoke. In addition, compared with PLA/7APP/3CNCs, the average amount of $\mathrm{CO}$ for PLA/7APP/3P/N-CNCs decreased, while the average amount of $\mathrm{CO}_{2}$ increased, indicating the increase of incomplete combustion substances, which was consistent with the trend of the increase of final char yield.

As shown in Fig. 6b, there was almost no residual char generated after pure PLA combustion. After $10 \%$ APP was added, the final char yield of the PLA composites was $6.5 \mathrm{wt} \%$. The carbon residue of the material decreased after replacing $3 \%$ APP with $3 \%$ CNCs, indicating that the char forming ability of the unmodified CNCs are poor. Compared with PLA/7APP/3CNCs, PLA/7APP/3P/N-CNCs has more residual char, even more than PLA/10APP. The final char yield of PLA/7APP/3P/N-CNCs was 6.8 wt\%. This result was consistent with the curves in Fig. $6 \mathrm{~b}$, in which $\mathrm{PLA} / 7 \mathrm{APP} / 3 \mathrm{P} / \mathrm{N}-\mathrm{CNCs}$ shows the lowest mass lost rate and the highest char residue. It indicates that P/N-CNCs play a flame retardant role in the condensed phase.

From Table 5, we also find that the time to ignition (TTI) of PLA composites containing flame retardants are shorter than that of pure PLA. This is because APP, CNCs and P/N-CNCs, as flame retardants, usually decompose before PLA, leading to shortening of the TTI of the material. In addition, the average effective heat of combustion (av-EHC) of PLA was significantly decreased after adding flame retardant, but the av-EHC of PLA/10APP, PLA/7APP/3CNCs and PLA/7APP/3P/N-CNCs had little difference. It showed that CNC and P/N-CNCs had little flame retardant effect in the gas phase. APP released large amount of inert gas during the combustion process, which played the main role of dilution effect in gas phase.

In summary, the synergistic flame retardant effect of APP and P/N-CNCs in inhibiting the peak heat release rate and mass loss of PLA matrix was better than that of APP and CNCs. That is because the synergistic flame retardant effect of P/N-CNCs and APP in the condensed phase is enhanced after being treated with modification agent containing phosphazene groups.

Table 5. Date of PLA composites obtained from cone calorimeter test 


\begin{tabular}{|c|c|c|c|c|c|c|c|c|}
\hline Samples & $\begin{array}{l}\text { TTI } \\
\text { (s) }\end{array}$ & $\begin{array}{l}\text { pk-HRR } \\
\left(\mathrm{kW} / \mathrm{m}^{2}\right)\end{array}$ & $\begin{array}{l}\text { THR } \\
\left(\mathrm{MJ} / \mathrm{m}^{2}\right)\end{array}$ & $\begin{array}{l}\text { av-EHC } \\
(\mathrm{MJ} / \mathrm{kg})\end{array}$ & $\begin{array}{l}\text { TSR } \\
\left(\mathrm{m}^{2} / \mathrm{m}^{2}\right)\end{array}$ & $\begin{array}{l}\text { av-CO } \\
(\mathrm{kg} / \mathrm{kg})\end{array}$ & $\begin{array}{l}\mathrm{av}-\mathrm{CO}_{2} \\
(\mathrm{~kg} / \mathrm{kg})\end{array}$ & $\begin{array}{l}\text { Char yield } \\
\text { (wt\%) }\end{array}$ \\
\hline Pure PLA & 44 & 561 & 84.7 & 20.0 & 50 & 0.0148 & 2.0325 & 0.1 \\
\hline PLA/10APP & 31 & 399 & 77.1 & 18.4 & 280 & 0.0285 & 1.8192 & 6.5 \\
\hline PLA/7APP/3CNCs & 27 & 282 & 70.0 & 18.3 & 238 & 0.0279 & 1.8422 & 5.2 \\
\hline PLA/7APP/3P/N-CNCs & 28 & 266 & 77.6 & 18.1 & 324 & 0.0307 & 1.7792 & 6.8 \\
\hline
\end{tabular}

\subsection{The analysis of residual char after cone calorimeter test}

In order to further study the flame-retardant mechanism of P/N-CNCs and APP in PLA, the surface morphology of the samples after cone calorimeter tests were analyzed in detail. As shown in Fig. 7, the char layer of PLA/10APP was thin and had obvious cracks. PLA/7APP/CNCs exhibited uneven distribution of carbon residue, while that of PLA/7APP/3P/N-CNCs was uniform and complete. In addition, it could be seen that PLA/7APP/3P/N-CNCs had more residual char than PLA/7APP/CNCs after burning and there was no obvious hole on the surface of the char layer. It demonstrated that APP with P/N-CNCs could effectively promote the formation of char layer.

The micromorphology of residual char for flame retardant PLA composites was further studied by SEM. And the relative element content in the char residue was determined by energy-dispersive X-ray (EDX). Fig. $\mathbf{8} \mathbf{a}_{1}, \mathbf{b}_{\mathbf{1}}$ and $\mathbf{c}_{\mathbf{1}}$ are the SEM images for the outer surface of the char residue, and $a_{2}, b_{2}$ and $c_{2}$ are for the inner surface. As shown in Fig. $\mathbf{8} a_{1}$, the outer surface of the char residue for PLA/10APP showed a typical morphology of intumescent char layer, but there were obvious holes. On the inner surface of the char residue in Fig. $\mathbf{8} \mathbf{a}_{2}$, it could also be seen that there were many voids or holes left, which was due to the release of the dilution gas decomposed by APP. As can be clearly observed from Fig. $\mathbf{8} b_{2}$, the inner surface of the char residue of PLA/7APP/3CNCs presented a fibrous char (marked with yellow arrow). This structure could maintain the structural integrity and provide the mechanical strength for the char layer. It means that CNCs not only provide carbon source for char layer, but also play the role of carbon layer skeleton. As can be clearly observed from Fig. $8 \mathbf{c}_{2}$, PLA/7APP/3P/N-CNCs also showed fibrous char, which were inherited from CNCs. However, unlike PLA/7APP/CNCs, there were many white particles on the carbon skeleton for PLA/7APP/P/N-CNCs, which were compounds containing silicon elements (Fig. $\mathbf{8} \mathbf{c}_{\mathbf{4}}$ ). Meanwhile, there were many small-sized char foams with closed pores on the fibrous carbon skeleton. In addition, the outer surface of PLA/7APP/P/N-CNCs was more compact and complete than that of PLA/7APP/3CNCs. The results of elemental analysis showed that not only silicon elements but also more nitrogen elements were locked in the carbon residue, which indicated that the phosphazene containing modification agent remained in the carbon residue and enhanced the flame retardancy of the condensed phase.

\subsection{The thermal stability of PLA composites}

The thermogravimetric tests of PLA composites were carried out in two different atmospheres. Its test curves are shown in Fig. 9, and the corresponding test data are shown in Table 6. It can be observed from Fig. 9 that the thermal degradation process of the samples in air atmosphere were similar to that in $\mathrm{N}_{2}$ atmosphere, with one-stage thermal degradation process. In $\mathrm{N}_{2}$ atmosphere, pure PLA exhibited high thermal stability, and its initial decomposition temperature was $355^{\circ} \mathrm{C}$, and only a small amount of residual char was generated at $700{ }^{\circ} \mathrm{C}$. After the addition of APP, the initial decomposition temperature of PLA/10APP was significantly lower than that of pure PLA, which was due to the partial decomposition of APP at low temperature. After further addition of CNCs, the initial decomposition temperature of the material was further reduced, because the thermal stability of CNCs was poor, which begins to decompose at $202.4^{\circ} \mathrm{C}$. Comparing with CNCs, the addition of $\mathrm{P} / \mathrm{N}$-CNCs can increase the initial decomposition temperature of flame retardant PLA composites from $337{ }^{\circ} \mathrm{C}$ to $340{ }^{\circ} \mathrm{C}$, because the thermal stability of CNCs can be improved by grafting modification agent containing phosphazene groups onto CNC. According to Table 6, $T_{\max }$ of PLA/7APP/3P/N-CNCs was the same as that of PLA/7APP/3CNCs, but the maximum decomposition rate was slower. The maximum mass loss rate (MLR) of PLA/7APP/3P/N-CNCs was $2.6 \mathrm{wt} \% /{ }^{\circ} \mathrm{C}$, which was lower than those of PLA/7APP/3CNCs $\left(2.9 \mathrm{wt} \% /{ }^{\circ} \mathrm{C}\right)$. The decrease of MLR indicated that the modified CNC could further inhibit the combustion of PLA/APP system. In addition, the residual char amount at $700{ }^{\circ} \mathrm{C}$ of $\mathrm{PLA} / 7 \mathrm{APP} / 3 \mathrm{P} / \mathrm{N}-\mathrm{CNCs}$ was $10.2 \mathrm{wt} \%$, which was slightly higher than that of PLA/7APP/3CNCs $(9.2 \%)$. This is because the carbonization capacity of $\mathrm{P} / \mathrm{N}-\mathrm{CNCs}$ is improved after the modification.

In air atmosphere, the initial decomposition temperature and the final carbon residue of PLA/7APP/3P/N-CNCs were higher than those of PLA/7APP/3CNCs. They had the same maximum decomposition temperature and smaller maximum decomposition rate. Compared with $\mathrm{PLA} / 7 \mathrm{APP} / 3 \mathrm{CNCs}\left(3.2 \mathrm{wt} \% /{ }^{\circ} \mathrm{C}\right)$, the maximum MLR of the PLA/7APP $/ 3 \mathrm{P} / \mathrm{N}-\mathrm{CNCs}\left(2.8 \mathrm{wt} \% /{ }^{\circ} \mathrm{C}\right)$ was reduced by $12.5 \%$. These results indicated that the modification of CNCs by grafting flame retardant agent containing phosphazene groups could promote the thermal stability and the char-forming ability of the PLA composite.

Table 6. Thermal behavior and charring parameters of PLA composites 


\begin{tabular}{|c|c|c|c|c|c|}
\hline \multicolumn{2}{|c|}{ Samples } & \multirow{2}{*}{$\begin{array}{l}T_{\mathrm{d}, 5 \%} \\
\left({ }^{\circ} \mathrm{C}\right) \\
355\end{array}$} & \multirow{2}{*}{$\begin{array}{l}T_{\max } \\
\left({ }^{\circ} \mathrm{C}\right) \\
378\end{array}$} & \multirow{2}{*}{$\begin{array}{l}\text { MLR } \\
\left(w t \% /{ }^{\circ} \mathrm{C}\right) \\
3.7\end{array}$} & \multirow{2}{*}{$\begin{array}{l}\text { Residuals at } 700{ }^{\circ} \mathrm{C}(\mathrm{wt} \%) \\
2.9\end{array}$} \\
\hline \multirow{4}{*}{$\mathrm{N}_{2}$} & Pure PLA & & & & \\
\hline & PLA/10APP & 344 & 375 & 2.7 & 9.2 \\
\hline & PLA/7APP/3CNCs & 337 & 374 & 2.9 & 9.2 \\
\hline & PLA/7APP/3P/N-CNCs & 340 & 374 & 2.6 & 10.2 \\
\hline \multirow{4}{*}{ Air } & Pure PLA & 349 & 386 & 4.3 & 2.2 \\
\hline & PLA/10APP & 344 & 375 & 3.3 & 9.5 \\
\hline & PLA/7APP/3CNCs & 339 & 374 & 3.2 & 7.1 \\
\hline & $\mathrm{PLA} / 7 \mathrm{APP} / 3 \mathrm{P} / \mathrm{N}-\mathrm{CNCs}$ & 341 & 374 & 2.8 & 9.2 \\
\hline
\end{tabular}

\subsection{The mechanical properties of PLA composites}

It was found that more and more applications require PLA composites to have good mechanical properties as well as excellent flame retardant properties (Chen et al. 2019). However, most of the flame retardants will reduce the mechanical properties of the materials (Huang et al. 2021; Singh et al. 2021; Yin et al.2018). As shown in Fig. 10, adding APP to PLA can significantly reduce the tensile strength and impact strength of the material. In Fig. 10, compared with PLA/10APP, the tensile strength of PLA/7APP/3CNCs was 35.8 MPa, which decreased slightly. The impact strength was $8.6 \mathrm{~kJ} / \mathrm{m}^{2}, 24.6 \%$ higher than that of PLA/10APP. As shown in Fig. 10a and 10b, comparing with PLA/7APP/3CNCs, the tensile strength of PLA/7APP/3P/N-CNCs increased from $35.8 \mathrm{MPa}$ to $38.4 \mathrm{MPa}$, the impact strength increased from $8.6 \mathrm{~kJ} / \mathrm{m}^{2}$ to $10.2 \mathrm{~kJ} / \mathrm{m}^{2}$, and the elongation at break increased from $1.7 \%$ to $2.2 \%$. It was worth noting that the PLA/7APP/3P/N-CNCs had the highest elongation at break. In general, PLA/7APP/3P/N-CNCs had the best mechanical properties among the flame retardant PLA composites. This is because the thermal stability of CNCs is improved by grafting flame retardant, which can mitigate the effect of decomposition during processing. Moreover, CNCs take advantage of large aspect ratio and benefit the mechanical properties of the material (Abraham E et al. 2016). These results indicate that the grafting treatment of CNCs give the material excellent flame retardancy and improve the mechanical properties at the same time.

The mechanical properties test results showed that the mechanical properties of the PLA composites were enhanced after the grafting of modification agent with phosphazene on CNCs. In order to further study the mechanism of improving the mechanical properties, the microstructure of the cross sections of the material after impact test were observed by scanning electron microscope. As shown in Fig. 11, after adding flame retardants, the impact cross section showed sea-island structures, and the flame retardant existed as dispersed phases. The cross section of PLA/10APP with uneven and filamented structure (yellow arrow) is presented in Fig. 11b. It indicated that PLA/10APP had good toughness. By comparing Fig. 11c and Fig. 11d, it was found that the flame retardant in PLA/7APP/3CNCs were not uniformly dispersed, while the section of PLA/7APP/3P/N-CNCs was rough and the dispersed phases were uniform. It is further proved that PLA/7APP/3P/N-CNCs has better toughness than PLA/7APP/3CNCs.

\section{Conclusion}

A kind of novel flame retardant cellulose nanocrystal (P/N-CNCs) containing phosphazene groups were successfully prepared, the synthesized $\mathrm{P} / \mathrm{N}-\mathrm{CNCs}$ were combined with APP or other phosphorus-containing flame retardants (MPP, AHP, PPAP) to construct an intumescent flame retardant system for PLA. The TGA results showed that P/N-CNCs had good thermal stability and excellent char-forming ability. Compared with CNCs, the $T_{\mathrm{d}, 5 \%}, T_{\max 1}$ and $T_{\max 2}$ of P/N-CNCs increased by $34.6 \%, 25.2 \%$ and $10.6 \%$ than that of CNCs. It was notable that the residual char yield at $700{ }^{\circ} \mathrm{C}$ of $\mathrm{P} / \mathrm{N}-\mathrm{CNCs}$ increased from $24.9 \mathrm{wt} \%$ (CNCs) to $55.8 \mathrm{wt} \%$. The limiting oxygen index and vertical combustion tests results indicated that APP combined with P/N-CNCs were beneficial to improve the LOI value and UL 94 rating of PLA compared with the other three phosphorus-containing flame retardants. PLA/7APP/3P/N-CNCs had the highest limit oxygen index value, which was $28.1 \%$, and reached UL 94 $\mathrm{V}-0$ rating. The cone calorimeter results showed that the synergistic flame retardant effect of APP and P/N-CNCs in inhibiting the peak heat release rate and mass loss of PLA matrix was better than that of APP and CNC. The pk-HRR value of PLA/7APP/3CNCs was $266 \mathrm{~kW} / \mathrm{m}^{2}$, which was lower than that of PLA/7APP/3P/N-CNCs $\left(282 \mathrm{~kW} / \mathrm{m}^{2}\right)$. In addition, compared with PLA/7APP/3CNCs, the tensile strength of $\mathrm{PLA} / 7 \mathrm{APP} / 3 \mathrm{P} / \mathrm{N}-\mathrm{CNCs}$ increased from $35.8 \mathrm{MPa}$ to $38.4 \mathrm{MPa}$, the impact strength increased from $8.6 \mathrm{~kJ} / \mathrm{m}^{2}$ to $10.2 \mathrm{~kJ} / \mathrm{m}^{2}$, and the elongation at break increased from 1.7 MPa to 2.2 MPa. This work provides a new idea for the design of cellulose nanocrystals with high thermal stability and outstanding charring ability, and offers a new method for the preparation of high-performance flame-retardant PLA composites.

\section{Declarations}


Financial support was provided by the National Nature Science Foundations (No.22175006, 51503008 and 51973006), the School Level Cultivation Fund of Beijing Technology and Business University for Distinguished and Excellent Young Scholars (BTBUYP2021).

Author contributions YC:Writing-Review \& Editing, Funding Acquisition, Supervision. HX:Investigation, Material preparation, Writing-Original Draft. ZS: Investigation, vertical burning test. BX:Supervision. JL:Supervision. LQ:Supervision, Funding Acquisition.

Ethical approval We declare that there is no financial or personal relationship between us and other people or organizations that may have an inappropriate impact on this work. All procedures performed in studies involving human participants were in accordance with the ethical standards of the institutional and/or national research committee and with the 1964 Helsinki declaration and its later amendments or comparable ethical standards. This article does not contain any studies with animals performed by any of the authors.

Informed consent Informed consent was obtained from all individual participants included in the study.

\section{References}

1. Sombatsompop N, Srimalanon P, Markpin T, Prapagdee B (2021) Polylactic Acid (PLA): Improve It, Use It, and Dump It Faster. BioResources 16(2):2196-2199

2. Hubbe M A, Lavoine N, Lucia L. A, Dou C (2021) Formulating Bioplastic Composites for Biodegradability, Recycling, and Performance: A Review. BioResources 16(1):2021-2083

3. Lyas RA, Sapuan SM, Harussani MM, Hakimi MYAY, Haziq MZM, Atikah MSN, Asyraf MRM, Ishak MR, Razman MR, Nurazzi NM (2021) Polylactic Acid (PLA) Biocomposite: Processing, Additive Manufacturing and Advanced Applications. Polymers 13(8):1326

4. Xu LF, Wu XD, Li LS, Chen YJ (2019) Synthesis of a novel polyphosphazene/triazine bi-group flame retardant in situ doping nano zinc oxide and its application in poly (lactic acid) resin. Polym Advan Technol 30(6):1375-1385

5. Xiong ZQ, Zhang Y, Du XY, Song PA, Fang ZP (2019) Green and Scalable Fabrication of Core-Shell Biobased Flame Retardants for Reducing Flammability of Polylactic Acid. ACS Sustainable Chem. Eng 7(9):8954-8963

6. Sharma S, Majumdar A, Butola B S (2021) Tailoring the biodegradability of polylactic acid (PLA) based films and ramie- PLA green composites by using selective additives. Int J Biol Macromol 181:1092-1103

7. Liu LB, Xu Y, Pan Y, Xu M J, Di YF, Li B (2021) Facile synthesis of an efficient phosphonamide flame retardant for simultaneous enhancement of fire safety and crystallization rate of poly (lactic acid). Chem Eng J 421:127761

8. Benito-Gonzalez I, Lopez-Rubio A, Gomez-Mascaraque LG, Martinez-Sanz M (2020) PLA coating improves the performance of renewable adsorbent pads based on cellulosic aerogels from aquatic waste biomass. Chem Eng J 390:124607

9. Jing J, Zhang Y, Fang ZP, Wang DY (2018) Core-shell flame retardant/graphene oxidehybrid : a selfassembly strategy towards reducing fire hazard and improving toughness of polylactic acid. Compos Sci Technol 165:161-167

10. Zhang SQ, Ye JW, Liu X, Wang Y, Li C, Fang JT, Chang BN, Qi Y, Li YC, Ning GL (2021) Titanium carbide/zeolite imidazole framework8/polylactic acid electrospun membrane for near-infrared regulated photothermal/ photodynamic therapy of drug-resistant bacterial infections. J. Colloid Interface Sci 599:390-403

11. Chen YJ, Mao XJ, Qian LJ, Yang CZ (2016) Flammability and anti-dripping behaviors of polylactide composite containing hyperbranched triazine compound. Integr Ferroelectr. 172(1):10-24

12. Zhang Y, Jing J, Liu T, Xi LD, Sai T, Ran SY, Fang ZP, Huo SQ, Song PA (2021) A molecularly engineered bioderived polyphosphate for enhanced flame retardant, UV-blocking and mechanical properties of poly(lactic acid). Chem Eng J 411:128493

13. Liu XH, Zhang QY, Peng B, Ren YL, Cheng BW, Ding C, Su XW, He J, Lin SG (2020) Flame retardant cellulosic fabrics via layer-by-layer selfassembly double coating with egg white protein and phytic acid. J Clean Prod 243:118641

14. Liu L. Zhu, MH, Shi YQ, Xu XD, Ma ZW, Fu SY, Yu B, Wang H, Song PA (2021) Functionalizing MXene towards highly stretchable, ultratough, fatigue- and fire-resistant polymer nanocomposites. Chem Eng J 424:130338.

15. Chen YJ, Li LS, Wu XD (2020) Construction of an efficient ternary flame retardant system for rigid polyurethane foam based on bi-phase flame retardant effect. Polym Advan Technol 31(12):3202-3210

16. Sai T, Ran SY, Guo ZH, Yan HQ, Zhang Y, Wang H, Song PA, Fang ZP (2021) Transparent, highly thermostable and flame retardant polycarbonate enabled by rod-like phosphorous-containing metal complex aggregates. Chem Eng J 409:128223

17. Chen YJ, Li LS, Qian LJ (2018) The pyrolysis behaviors of phosphorus-containing organosilicon compound modified ammonium polyphosphate with different phosphorus-containing groups, and their different flame-retardant mechanisms in polyurethane foam. RSC Adv 8(48):27470-27480 
18. He WT, Song PA, Yu B, Fang ZP, Wang H (2020) Flame retardant polymeric nanocomposites through the combination of nanomaterials and conventional flame retardants. Prog Mater Sci 114:100687

19. Li LS, Mao XJ, Ju R, Chen YJ, Qian LJ (2018) Synergistic effect of organo-montmorillonite on intumescent flame-retardant PLA. Integr Ferroelectr 527(1):25-26

20. Costes L, Laoutid F, Brohez S, Dubois P (2017) Bio-based flame retardants: When nature meets fire protection. Mater. Sci. Eng. R Rep 117:125

21. Chen YJ, Wu XD, Qian LJ (2020) Flame-retardant behavior and protective layer effect of phosphazene-triazine bi-group flame retardant on polycarbonate. J Appl Polym Sci 3:e49523.

22. Song Y, Zong X, Wang N, Yan N, Shan XY, Li JC Preparation of gamma-Divinyl-3-Aminopropyltriethoxysilane Modified Lignin and Its Application in Flame Retardant Poly(lactic acid). Materials 11:1505

23. Zhang Y, Han PY, Fang ZP (2018) Synthesis of phospholipidated -cyclodextrin and its application for flame-retardant poly(lactic acid) with ammonium polyphosphate, J Appl Polym Sci 135:46054

24. Luda MP, Zanetti M (2019) Cyclodextrins and cyclodextrin derivatives as green char promoters in flame retardants formulations for polymeric materials. A review. Polymers 11:664.

25. Zhang Y, Xiong ZQ, Ge HD, Ni LK, Zhang T, Huo SQ, Song PA, Fang ZP (2020) Core-Shell Bioderived Flame Retardants Based on Chitosan/Alginate Coated Ammonia Polyphosphate for Enhancing Flame Retardancy of Polylactic Acid. ACS Sustainable Chem. Eng 8(16):6402-6412

26. Yang HT, Yu B, Xu XD, Bourbigot S, Wang H, Song PA (2020) Lignin-derived bio-based flame retardants toward high-performance sustainable polymeric materials. Green Chemistry. 22(7):2129-2161

27. Wang XF, Xing WY, Wang BB, Wen PY, Song L, Y, Zhang P (2013) Comparative study on the effect of beta-cyclodextrin and polypseudorotaxane as carbon sources on the thermal stability and flame retardance of polylactic acid. Ind Eng Chem Res 52(9):3287-3294

28. Maqsood M, Langensiepen F, Seide G (2019) The efficiency of biobased carbonization agent and intumescent flame retardant on flame retardancy of biopolymer composites and investigation of their melt-spinnability, Molecules 24(8)1513

29. Chen C, Gu XY, Jin XD, Sun J, Zhang S (2017) The effect of chitosan on the flammability and thermal stability of polylactic acid/ammonium polyphosphate biocomposites. Carbohyd Polym 157:1586-1593

30. Maqsood M, Seide G (2020) Improved thermal processing of polylactic acid/oxidized starch composites and flame-retardant behavior of intumescent non-wovens. Coatings 10:291

31. Thomas B, Raj MC, Athira KB, Jithin Joy H, Moores A, Drisko G, Sanchez C (2018) Nanocellulose, a versatile green platform: From biosources to materials and their applications. Chemical Reviews 118 (24) 11575-11625

32. De France KJ, Hoare T, Cranston ED (2017) Review of Hydrogels and Aerogels Containing Nanocellulose. Chem Mater 29(11):4609-4631

33. Abraham E, Kam D, Nevo Y, Slattegard R, Rivkin A, Lapidot S, Shoseyov O (2016) Highly Modified Cellulose Nanocrystals and Formation of EpoxyNanocrystalline Cellulose (CNC) Nanocomposites. ACS Appl Mater Inter 8(41):28086-28095

34. Mohammadi N, Heuzey MC, Carreau PJ, Taguet A (2021) Morphological and Rheological Properties of PLA, PBAT, and PLA/PBAT Blend Nanocomposites Containing CNCs. Nanomaterials 11(4):857

35. Feng JB, Sun YQ, Song PA, Lei WW, Wu Q, Liu LN, Yu YM, Wang H (2017) Fire-Resistant, Strong, and Green Polymer Nanocomposites Based on Poly(lactic acid) and Core-Shell Nanofibrous Flame Retardants. Acs Sustain Chem. Eng 5(9):7894-7904

36. Ruiz-Palomero C, Soriano ML, Valcárcel MJ. (2015) beta-

Cyclodextrin decorated nanocellulose: a smart approach towards the selective fluorimetric determination of danofloxacin in milk samplesm. Analyst 140(10):3431-3438.

37. Mekonnen TH, Haile T, Ly M (2021) Hydrophobic functionalization of cellulose nanocrystals for enhanced corrosion resistance of polyurethane nanocomposite coatings. Appl Surf Sci 540(2021):148299

38. Szefer E, Leszczynska A, Hebda E, Pielichowski K (2021) The Application of Cellulose Nanocrystals Modified with Succinic Anhydride under the Microwave Irradiation for Preparation of Polylactic Acid Nanocomposites. J Renew Mater 9(6):1127-1142

39. Tajmoradi Z, Roghani-Mamaqani H, Salami-Kalajahi M (2021) Cellulose nanocrystal-grafted multi-responsive copolymers containing cleavable o-nitrobenzyl ester units for stimuli-stabilization of oil-in-water droplets. Chem Eng J 417:128005.

40. Che KM, Zhang MZ, He JL, Ni PH (2020) Polyphosphoester-modified Cellulose Nanocrystals for Stabilizing Pickering Emulsion Polymerization of Styrene. Chinese J Polym Sci 38(9):321-931

41. French AD (2017) Glucose, not cellobiose, is the repeating unit of cellulose and why that is important. Cellulose (2017) 24:4605-4609

42. Ling Z, Wang T, Makarem M, Cintron MS, Cheng HN, Kang X, Bacher M, Potthast A, Rosenau T, King H, Delhom CD, Nam S, Edwards JV, Kim SH, Xu F, French AD (2019) Effects of ball milling on the structure of cotton cellulose. Cellulose (2019) 26:305-328

43. French AD (2014) Idealized powder diffraction patterns for cellulose polymorphs. Cellulose 21:885-896

Page 10/17 
44. Chen YJ, Li LS, Xu LF, Qian LJ (2018) Phosphorus-containing silica gel-coated ammonium polyphosphate: Preparation, characterization, and its effect on the flame retardancy of rigid polyurethane foam. J Appl Polym Sci 135(22):46334

45. Ma KB, Yun H, Wu NJ, Niu FK, Yu JH (2021) Superior Water-Resistant Poly(2-hydroxyethyl methacrylate phosphate) Flame Retardant and a Transparent, Flame-Retardant, and Biodegradable Poly(lactide) Blend Film. ACS Appl. Polym. Mater 3(3):1314-1323

46. Zhou ZY, Lin YC, Tawiah B, Sun J, Yuen RKK, Fei B (2021) DOPO-Decorated Two-Dimensional MXene Nanosheets for Flame-Retardant, Ultraviolet-Protective, and Reinforced Polylactide Composites. Acs Appl Mater Inter 13(18):21876-21887

47. Gao DD, Wen X, Guan YY, Czerwonko W, Li YH, Gao Y, Mijowska E, Tang T (2020) Flame retardant effect and mechanism of nanosized NiO as synergist in PLA/APP/CSi-MCA composites. Compos Commun 17:170-176

48. Li LS, Chen YJ, Wu XD, Xu B, Qian LJ (2019) Bi-phase flame-retardant effect of dimethyl methylphosphonate and modified ammonium polyphosphate on rigid polyurethane foam. Polym Advan Technol 30(11):2721-2728

49. Chen YJ, Xu LF, Wu XD, Xu B (2019) The influence of nano ZnO coated by phosphazene/triazine bi-group molecular on the flame retardant property and mechanical property of intumescent flame retardant poly (lactic acid) composites. Thermochim Acta 679:178336

50. Huang GB, Chen W, Wu T, Guo HC, Fu CY, Xue YJ, Wang K, Song PA (2021) Multifunctional graphene-based nano-additives toward highperformance polymer nanocomposites with enhanced mechanical, thermal, flame retardancy and smoke suppressive properties. Chem Eng J 410:127590

51. Singh T, Lendvai L, Dogossy G, Fekete G (2021) Physical, mechanical, and thermal properties of Dalbergia sissoo wood waste-filled poly(lactic acid) composites Polym Composite 2021

52. Yin WD, Chen L, Lu FZ, Song PA, Dai JF, Meng LH (2018) Mechanically Robust, Flame-Retardant Poly(lactic acid) Biocomposites via Combining Cellulose Nanofibers and Ammonium Polyphosphate. ACS Omega 3(5):5615-5626

\section{Figures}




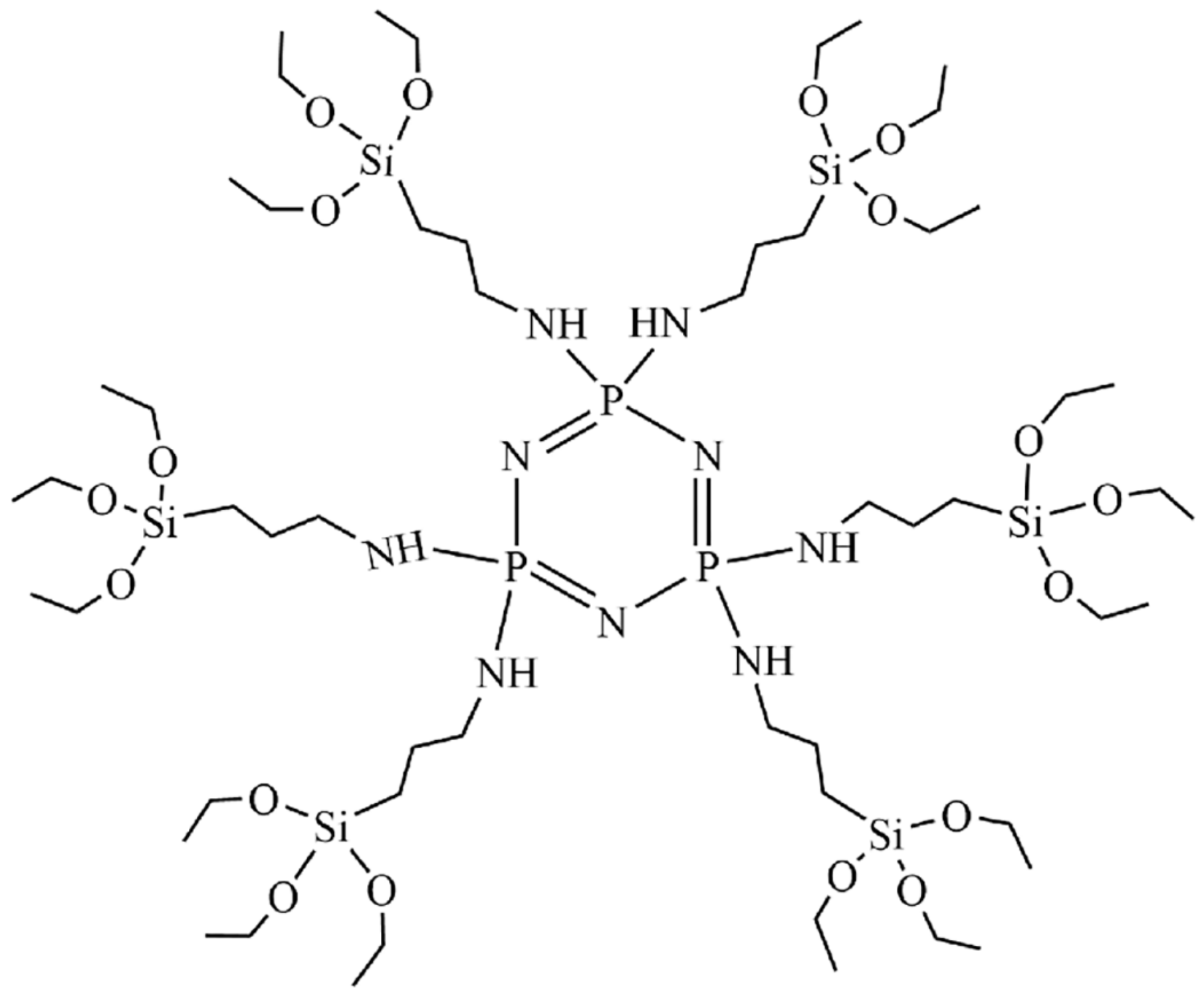

Figure 1

Chemical structure of modification agent

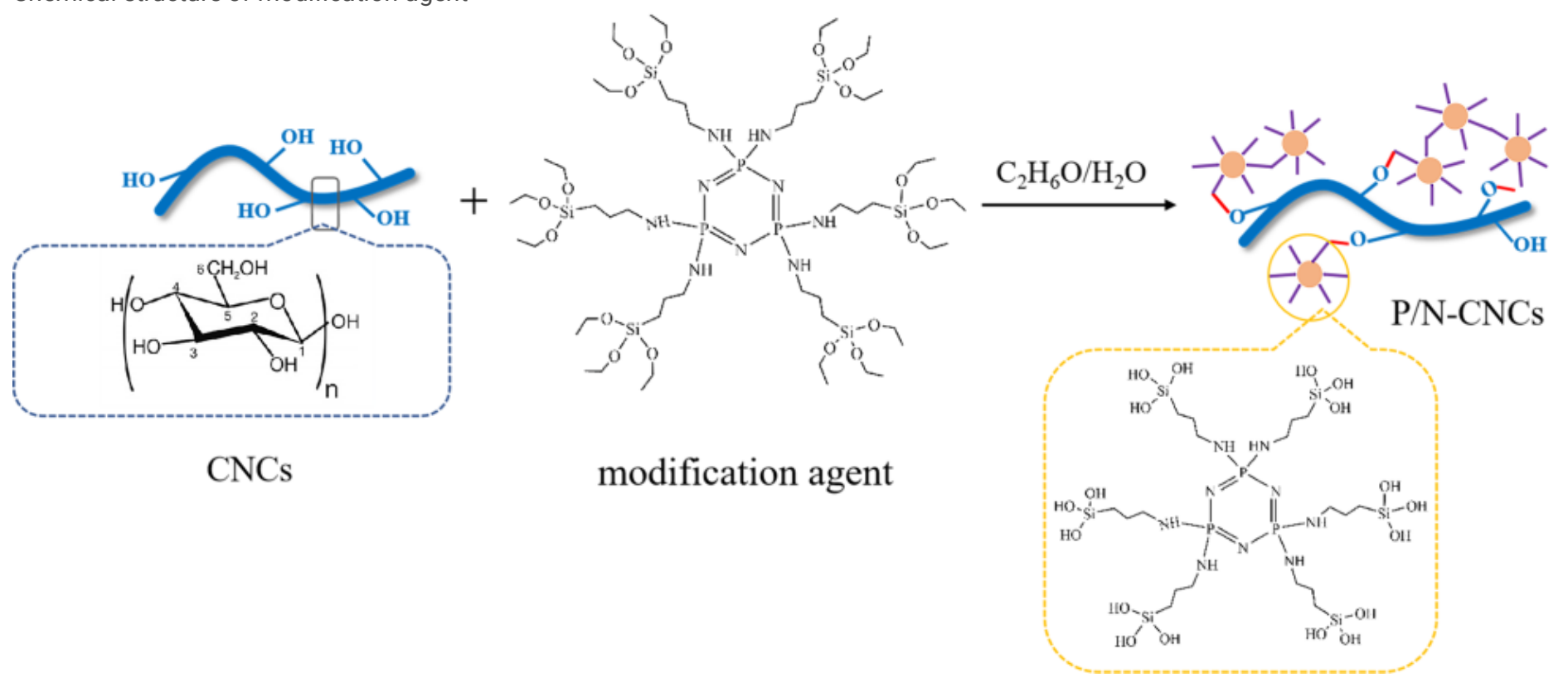


Figure 2

Schematic illustration for the synthetic route to P/N-CNCs
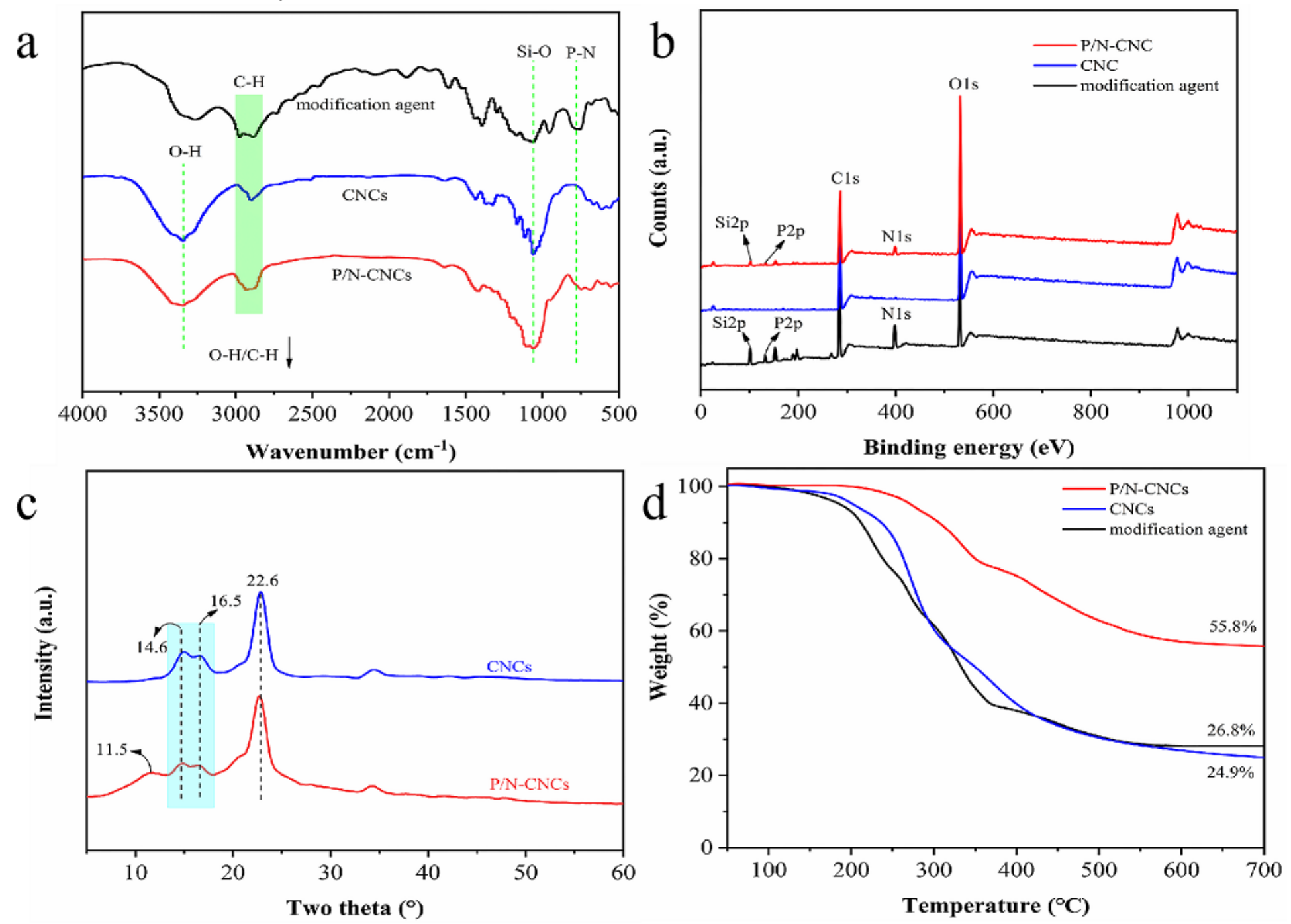

Figure 3

(a) FTIR spectra of modification agent, CNCs and P/N-CNCs, (b) XPS surveys of modification agents, CNCs and P/N-CNCs, (c) XRD patterns of CNCs and P/N-CNCs, and (d) TGA curves of CNCs and P/N-CNCs 

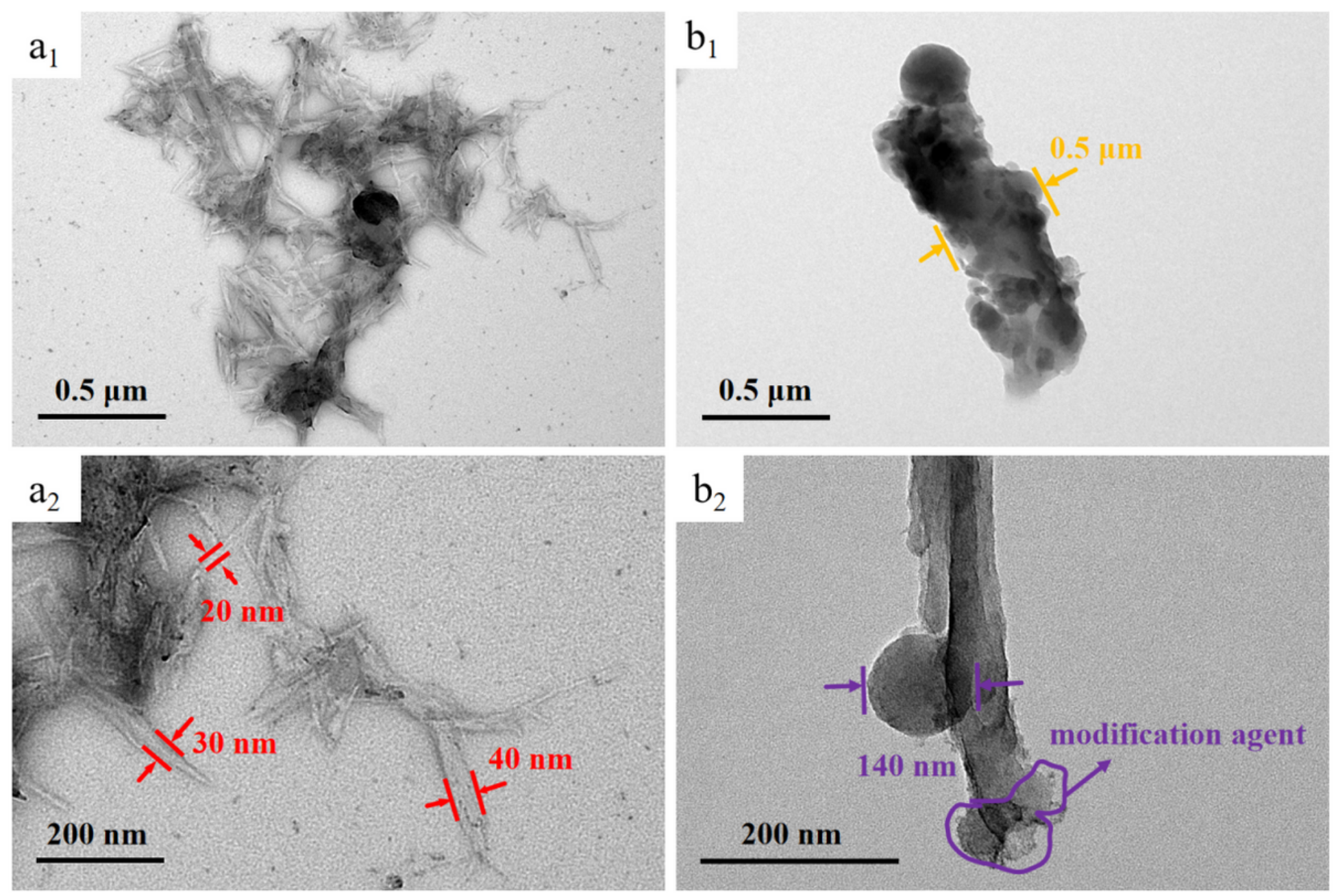

Figure 4

TEM images of CNCs (a1, a2) and P/N-CNCs (b1, b2)

As

\section{Figure 5}

The digital photos of (a) PLA/10APP, (b) PLA/7APP/3CNCs, (c) PLA/7APP /3P/N-CNCs, (d) PLA/7MPP/3P/N-CNCs, (e) PLA/7AHP/3P/N-CNCs, and (f) PLA/7PPAP /3P/N-CNCs, flame in the vertical burning test.
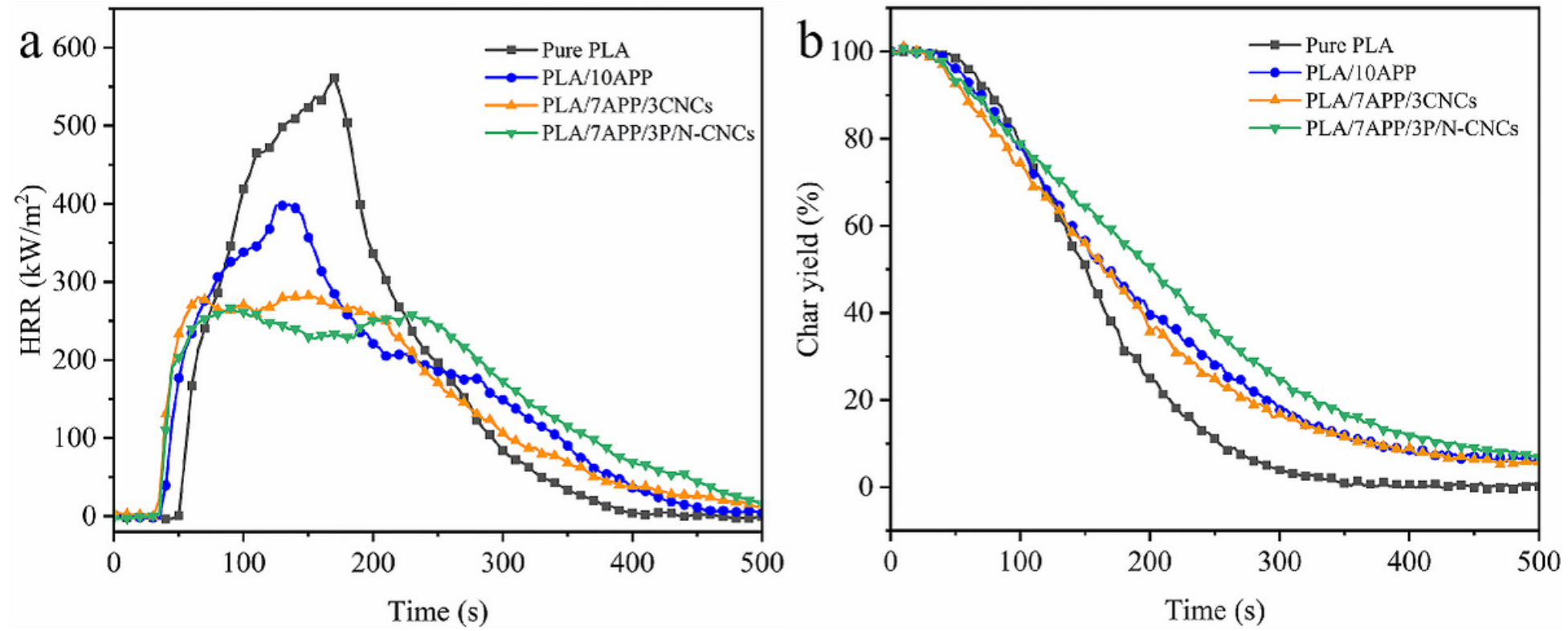


\section{Figure 6}

HRR (a) and Char yield (b) curves of PLA composites

A

\section{Figure 7}

Residual char digital photos of PLA/10APP (a), PLA/7APP/3CNCs (b) and PLA/7APP/3P/N-CNCs (c)
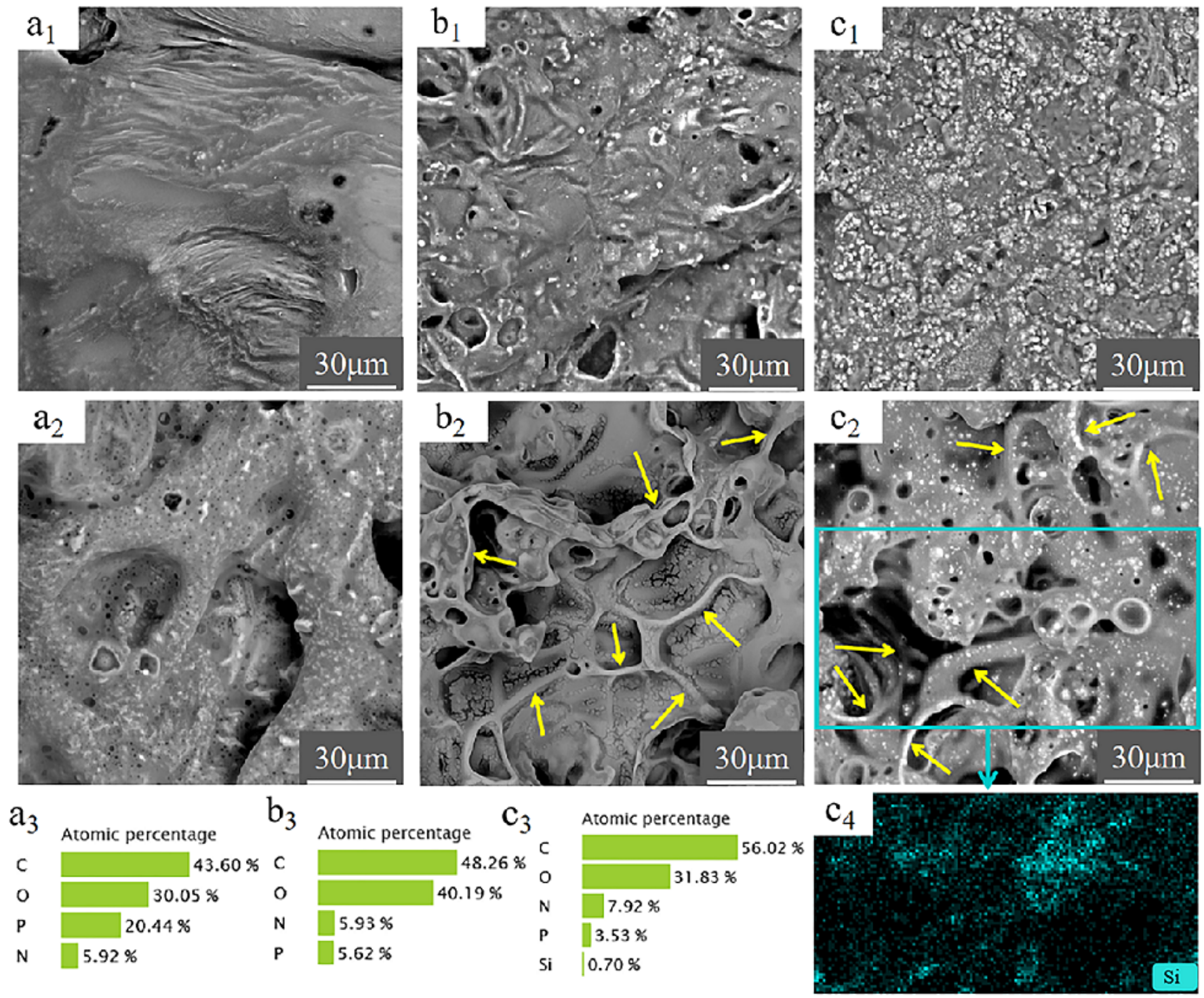

Figure 8

SEM images and corresponding chemical compositions of the char residue for (a1, a2, a3) PLA/10APP, (b1, b2, b3) PLA/7APP/3CNCs and (c1, c2, c3) PLA/7APP/3P/N-CNCs together with (c4) EDX mapping patterns for PLA/7APP/3P/N-CNCs. 

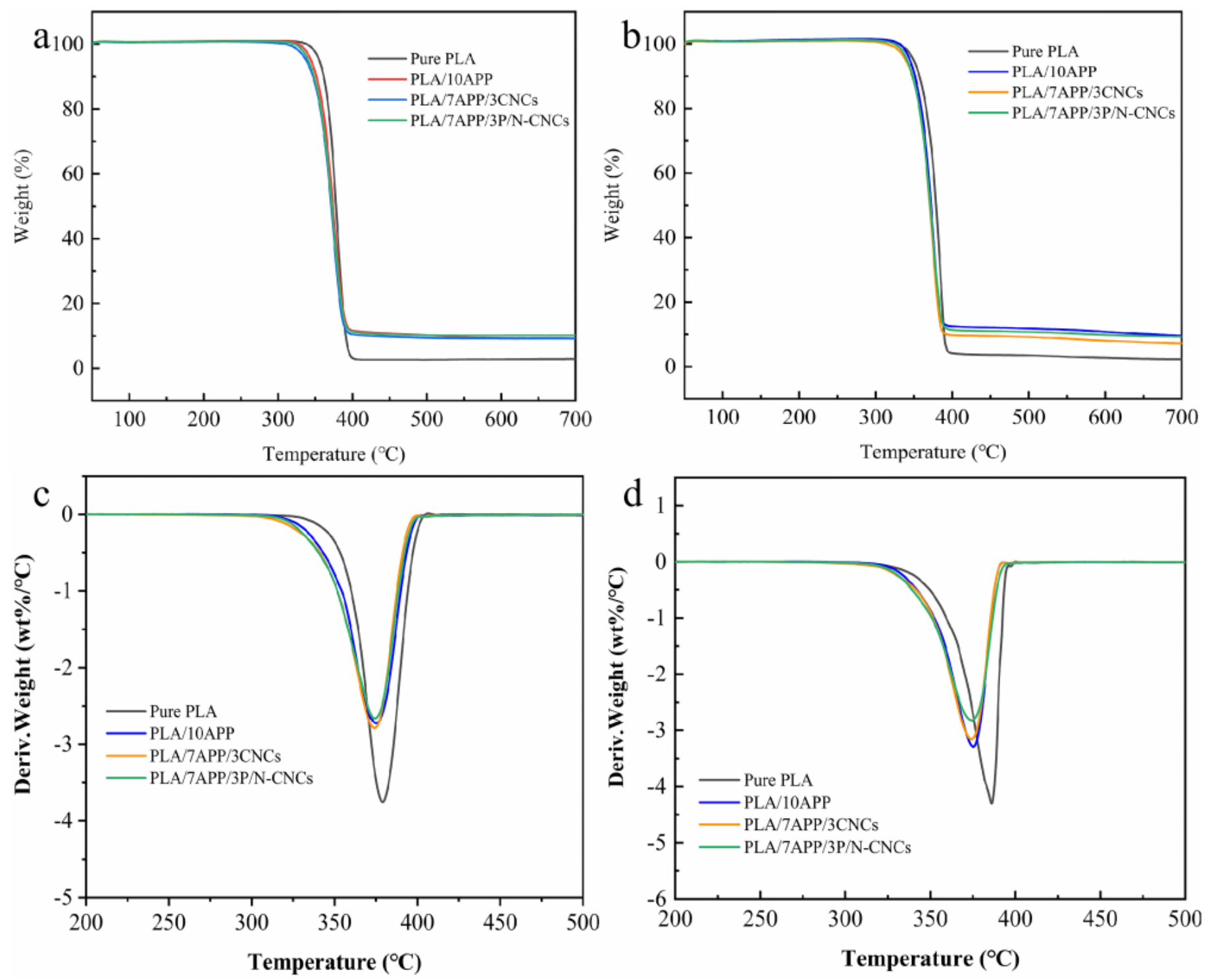

Figure 9

TG and DTG curves of PLA composites in N2 $(a, c)$ and air $(b, d)$ atmospheres
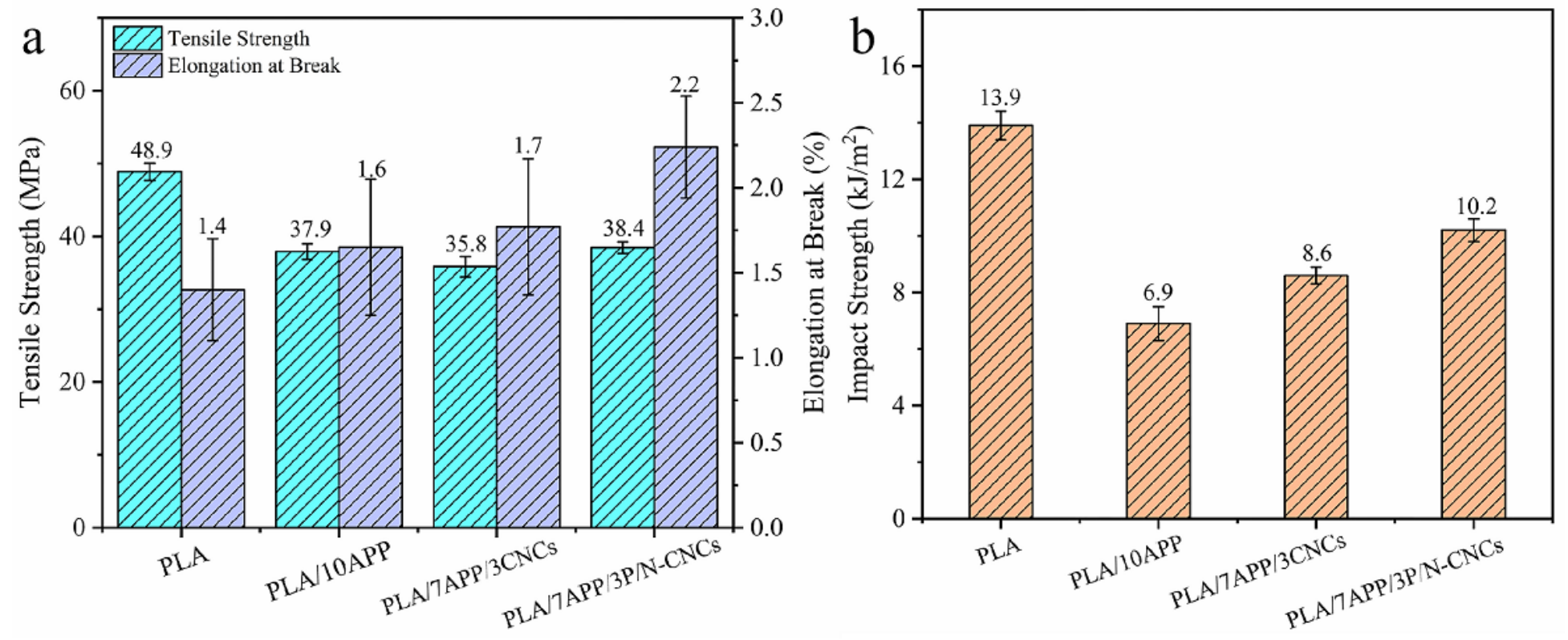
Figure 10

Tensile strength(a), elongation at break (a) and impact strength (b) of PLA composites

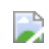

\section{Figure 11}

Microtopography for the impact fractured surface of pure PLA (a), PLA/10APP (b), PLA/7APP/3CNCs (c) and PLA/7APP/3P/N-CNCs (d) (SEM1000x).

\section{Supplementary Files}

This is a list of supplementary files associated with this preprint. Click to download.

- GraphicalAbstract.tif 